\title{
WASP Model-based Optimization on Water Quality Monitoring Section in Ningxia Segment of the Yellow River
}

\author{
Meng Xiangyi ${ }^{1}$, Qi Jingwen ${ }^{1}$,Qian Hui ${ }^{1 * \star}$ and Li Mengna ${ }^{1}$ \\ ${ }^{1}$ School of Environmental Science and Engineering, Chang'an University, Shaanxi, China
}

\begin{abstract}
According to the hydrographic features and current data of Yellow River's Ningxia Sector, this study uses WASP model for water quality simulation and selects three pollution indexes COD, NH3-N and TP, conducting analysis on the spatial change characteristics of these three indexes. On this basis, the study optimizes the water quality monitoring section and finds that the existing 6 monitoring sections are reasonably set up and the supervision data gathered from them could well reflect the water quality changes along the way. However, the lack of monitoring on water quality changes between the lower river bank and the Jinshawan section inspires our proposal to add a monitoring section near Zhongning County, so that the warning against and management of the water quality of Yellow River's Ningxia Sector would have more detailed and reliable grounds.
\end{abstract}

\section{Introduction}

In the monitoring and management of water environment, whether the water quality monitoring sections are set up in a reasonable and scientific manner has a direct impact on the accuracy and efficiency of water quality monitoring. Therefore, the set-up and management of monitoring section is a critical foundation for the work ${ }^{[1]}$. As one of the six Chinese provinces facing severe problem of lack of water, Ningxia is facing more and more water quality-fuelled water shortage problems in recent years. As Ningxia's most important source of water, the Yellow River's water quality status has highly impact on the quality of water usage in Ningxia region ${ }^{[2]}$. Therefore, the optimization of water quality monitoring section in Yellow River's Ningxia Sector has important significance.

Common water quality monitoring methods include: the traditional approach which mainly relies on relevant demand and set-up procedures ${ }^{[3]}$; mathematical statistical methods such as matter element analysis ${ }^{[4]}$, fuzzy cluster analysis $^{[5]}$, variance analysis and historic data estimate method as well as the model-based comprehensive analysis method ${ }^{[6][7]}$. Wherein, the third method is relatively accurate and intuitive and is so far rarely used in China. WASP is a water quality model system proposed by the environmental protection agency. It can be used to simulate the water quality of rivers, lakes, estuaries and coastal waters. This model is used widely, and the WASP is conducive to the development of the mode because its source code is completely open ${ }^{[8-10]}$. Therefore, this paper uses already available data and selects WASP model, to conduct simulation and optimization based on the third method above.

\section{Model Generalization}

Considering local environmental conditions, the mainstream of Yellow River in Ningxia is divided into the lower river bank -Qingtongxia Section (Weining Section) and Qingtongxia-Shizuishan Section (Qingshi Section). Combining the actually measured landform data, the Yellow River's Weining Section is generalized into 27 sections, and the Qingshi Section into 44 sections, as shown in Figure 1 and 2. The section data obtained from the calculation of Weining Section is imported into the model as the initial conditions for Qingshi Section. The water volume of each section, the characteristic distance between neighbouring sub-sections and sectional area of sub-sections are respectively calculated as the model's input conditions. Major input variables for the Yellow River's pollutants include branches flowing into the Yellow River, drain ditches and direct discharge points; the output variable is mainly the irrigation with the Yellow River water..

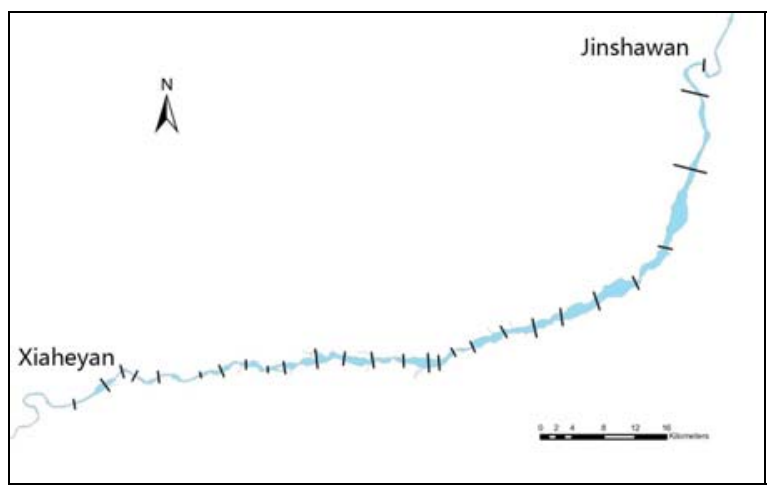

Fig. 1 Model generalization diagram of Weining section 


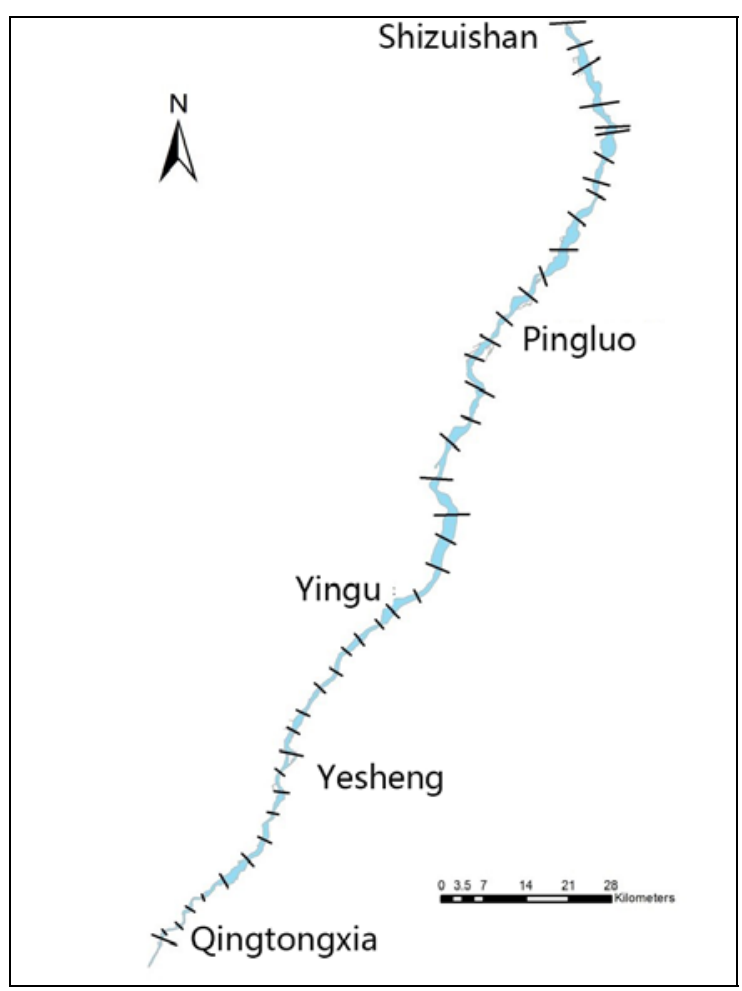

Fig. 2 Model generalization diagram of Qingshi section

\section{Model establishment and verification}

The water quality model is established with 2011 being the foundation year. The model uses EUTRO module and the time step is established as 1 . Based on existing information, COD, NH3-N and TP are selected, and then we successively input relevant parameters of the river sections such as the initial concentration, boundary concentration, oxygen content and water temperature, etc. Some of the model's parameters refer to WASP's user manual for set-up. COD, NH3-N and TP self-purification coefficient are obtained from indoor degradation experiment of water sample from the Yellow River's upstream, midstream and downstream, registering 0.05/d, $0.015 / \mathrm{d}$ and $0.025 / \mathrm{d}$, respectively; the longitudinal dispersion coefficient of pollutants values at $50 \mathrm{~m}^{2} / \mathrm{s}$ as the model's input parameter.

The roughness value reflects the effect of riverbed's roughness on water flow, which is related to multiple factors such as water depth, rate of fall, riverbed composite, geometric shape of the section, water plane form, etc. It is the key to calculating the water surface profile. On the basis of massive literatures ${ }^{[11-15]}$, upon repeated survey and completing parameter calibration and model verification, the value of $n$, the comprehensive roughness of river course, are determined. We finally obtained comprehensive river course roughness values of the Weining Section and Qingshi Section at 0.045 and 0.036 respectively. The comparison between the water level calculation process and the actually measured values in 2011 of the Yellow River Weining Section Shentan Sub-section and the Yellow River Qingshi Section's Gaoren Town Sub-section are reflected in the Fig. 3 and Fig. 4 respectively. The figures show that the water level tolerance is within $0.16 \mathrm{~m}$ and satisfied the model's accuracy requirement.

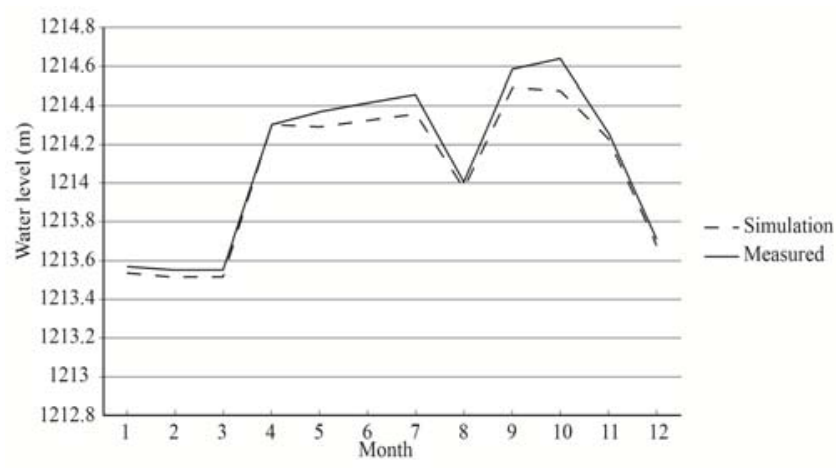

Fig. 3 Comparison between the water level calculation process and the measured values of the Yellow River Weining Section Shentan Sub-section

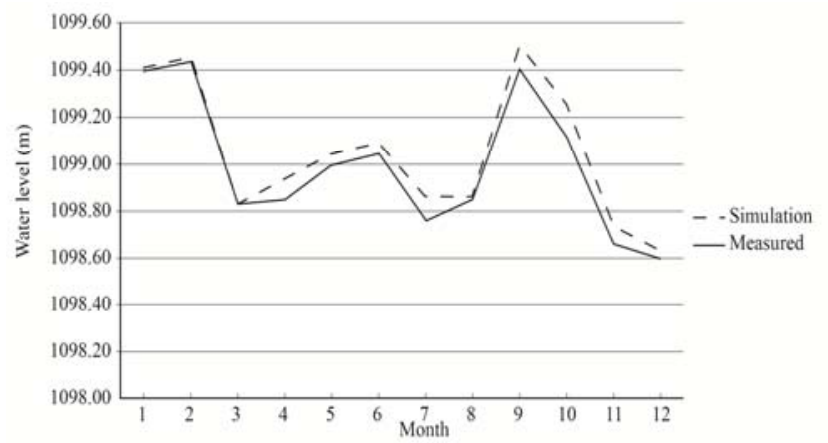

Fig. 4 Comparison between the water level calculation process and the measured values of the Yellow River Qingshi Section Shentan Sub-section

Based on the hydrodynamics model, the calibration of the Yellow River's mainstream water quality model is completed. Figs. 5 to 7 are respectively the comparison diagram between the simulation values and actually measured values in 2011 of three indexes: the COD, NH3-N and TP at the Qingtongxia section. The relative error of each water quality index's simulation value and actually measured value at the section is calculated to be lower than $20 \%$, reaching the model's requirement on accuracy.

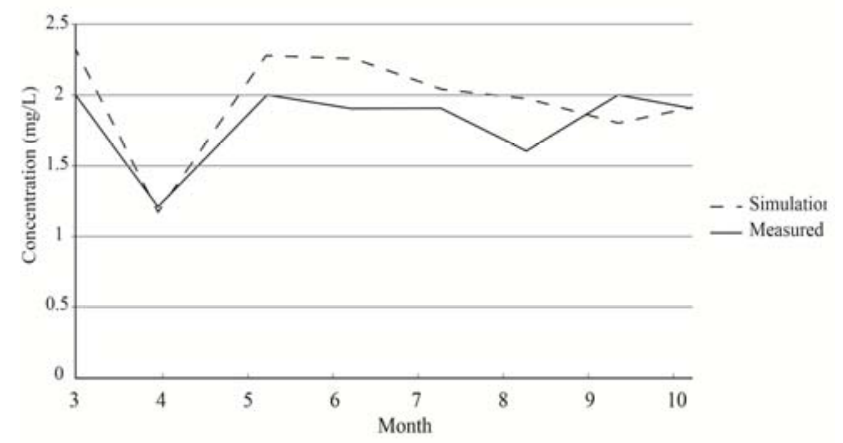

Fig. 5 Comparison diagram between the simulation values and actually measured values of COD 


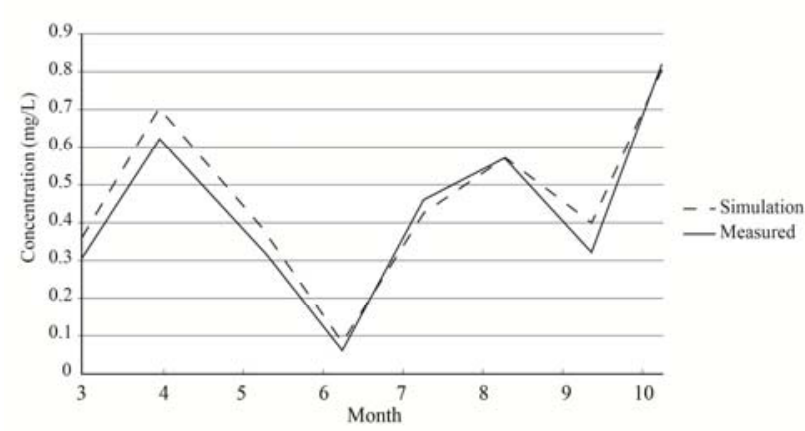

Fig. 6 Comparison diagram between the simulation values and actually measured values of NH3-N

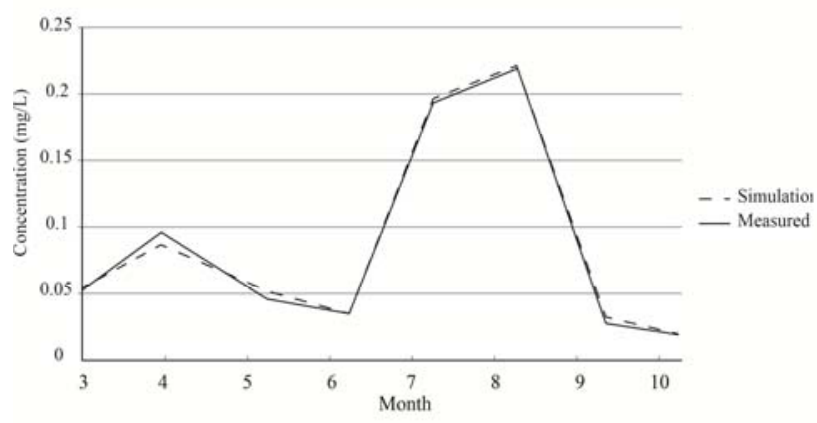

Fig. 7 Comparison diagram between the simulation values and actually measured values of TP

\section{Results and Discussion}

This study selects Year 2011 with more available information for water quality simulation of the Yellow River's mainstream. Due to the difference of water content in different periods, and the amount of water has important influence on the concentration of pollutants. This study adopts change-point analysis to divide water period of lower river bank in 2011, respectively determining the high-water period (June6 September), normal-water period (April May, October November) and dry period (January March, December). We analyse the spatial variation characteristics of the three pollution indexes. The results were reflected in figures 10, 11 and 12.

From Fig. 8 we known that, during the high-water period, normal-water period and dry period, the COD concentration could reach or exceed the water quality standard of Category II ground water. Wherein, in the dry period, the COD concentration from the Qingtongxia subsection to the Yesheng Road sub-section reaches the water quality standard as Category I ground water. In general, the Yellow River's mainstream at Ningxia sector suffers less severe COD pollution. In different water level periods, COD concentration basically shows consistent changing pattern along the way, with the increased concentration mainly being the result of sewage discharge from the drainage ditch. Among them, near the Qingtongxia section, the COD concentration values all show significant reduction mainly due to the water reservoir's storage and regulation effect, diluting the pollutants and significantly reduced concentration.

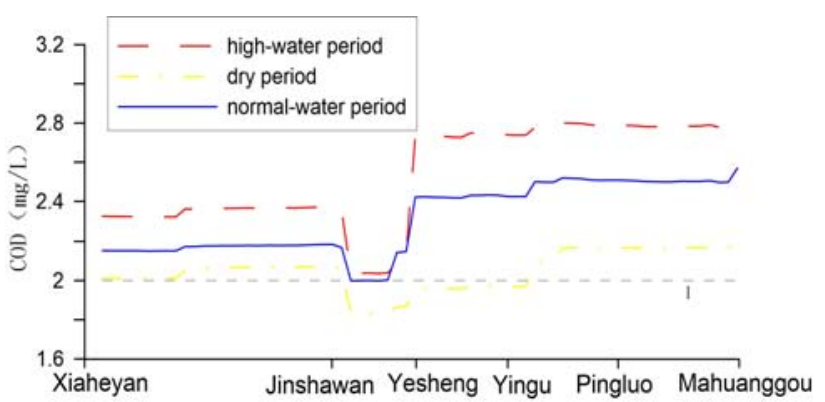

Fig. 8 Spatial change curve of COD concentration of water along the mainstream of the Yellow River

From Fig. 9 we can see that, during the high-water period, normal-water period and dry period, NH3-N concentration shows obvious increasing trend along the way, transforming the Category II water into Category III water. During the high-water period, the sector from the lower river bank to the Yesheng road bridge's ground water quality reaches Category II standard. Coming to the Mahuanggou section, the NH3-N concentration has risen to around $0.8 \mathrm{mg} / \mathrm{L}$; during the normal-water period, NH3-N concentration could maintain the Category II ground water quality standard; during the dry period, the NH3-N concentration near the Yingu road bridge section exceeds the Category II water quality standard and maintains Category III water quality standard all the way to the boundary section at approximately $0.7 \mathrm{mg} / \mathrm{L}$.

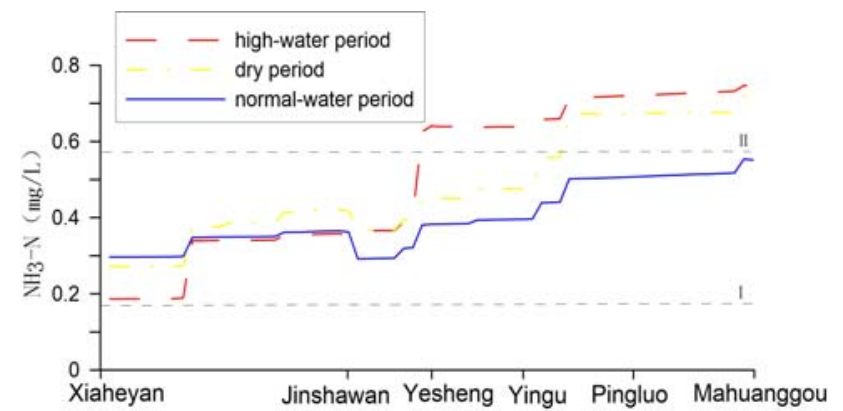

Fig. 9 Spatial change curve of NH3-N concentration of water along the mainstream of the Yellow River

Fig.10 shows that TP concentration has minor changes along the way and the TP concentration's spatial change trends in different water period are basically the same, only decreasing a little bit near the Qingtongxia section. During the high-water period, TP concentration values all meet the Category III water quality standard; during the normal-water period, TP concentration values from the lower river bank section to the Yingu road bridge section fall within the range of Category II water quality standard with minor pollution, and then reaches Category II water quality standard after the Yingu road bridge section; during the dry period, TP concentration values all meet Category II water quality standard. 


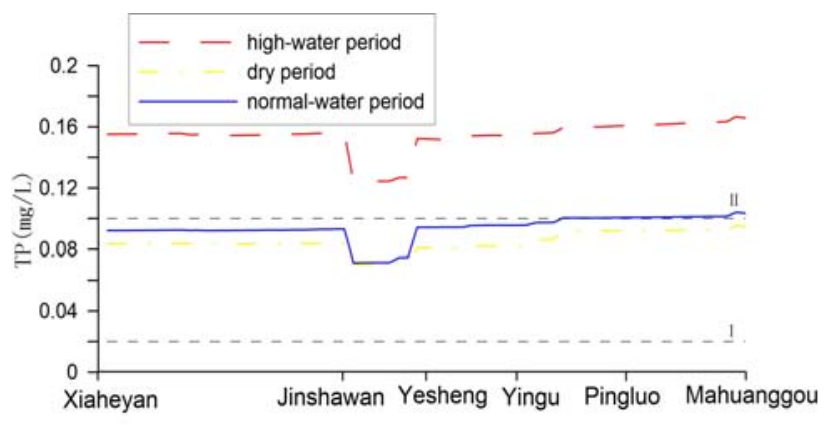

Fig. 10 Spatial change curve of TP concentration of water along the mainstream of the Yellow River

Operation results above show that the current 6 monitoring sections are reasonably set up in accurate positions and their monitoring data could well reflect water quality changes along Yellow River's Ningxia Sector. However, about in the middle of the sector from the lower river bank to the Jinshawan section, the join-in of the Qingshui River and the first row of ditches leads to significant changes of some water quality indexes (such as the COD concentration and NH3-N concentration), it is therefore proposes to add another monitoring section near Zhongning County for more comprehensive monitoring on water quality changes, offering more detailed and reliable grounds for water quality warning and management on the Yellow River's Ningxia Sector. At the same time, the monitoring on the water quality in the high-water period (June - September) should be reinforced.

\section{Conclusions}

(1) According to the Yellow River's Ningxia Sector's hydrographic features and actual local conditions, this study uses WASP model for water quality simulation. Upon verification, the water level tolerance is within $0.16 \mathrm{~m}$, meeting the model's requirement on accuracy. Based on the hydrodynamics model, the calibration of the Yellow River's mainstream water quality model is completed. Wherein, the model simulation values and actually measured values of three indexes - the CODMn, NH3-N and TP - show an absolute value of relevant error of less than $20 \%$, reaching the model's requirement on accuracy.

(2) In general, the Yellow River mainstream's Ningxia sector has low COD pollution. During different water periods, COD concentration basically shows consistent changing trend along the way, with the sewage discharge from ditches being the main factor for increased concentration. Wherein, near Qingtongxia section, CODMn concentration values all show significant drop mainly due to the water reservoir's storage and regulation effect which dilutes the pollutants. NH3-N concentration shows significant increasing trend along the way, transforming the Category II water into Category III water. TP concentration has minor changes along the way and the TP concentration's spatial change trends in different water period are basically the same, only decreasing a little bit near the Qingtongxia section.

(3) The current 6 monitoring sections are reasonably set up in accurate positions and their monitoring data could well reflect water quality changes along Yellow River's Ningxia Sector. It is recommended to add another monitoring section near Zhongning County (approximately the middle point from the lower river bank section to the Jinshawan section) for more comprehensive monitoring on water quality changes. At the same time, the monitoring on the water quality in the high-water period (June - September) should be reinforced in order to offer more detailed and reliable grounds for water quality warning and management on the Yellow River's Ningxia Sector.

\section{Acknowledgments}

This paper was supported by the National Natural Science Foundation of China (41172212)

\section{References}

[1] Zhang L., Hao Y.Q., Jiang Y., Environmental Monitoring And Forewarning 3, 54-56 (2011)

[2] Wu H.X., China Water Resources 3, 23-24 (2011)

[3] Wang Z.P., Meng X.L., Huo Q.G., Environmental Monitoring In China 19, 15-18 (2003)

[4] Fan Y.Q., Li H., Liu T.T., Yellow River 34, 8284(2012)

[5] Ma F., Jiang L., Inner Mongolia Environmental Protection, 18, 48-50 (2006)

[6] Qu M.L., Study On Monitoring Indexes And Monitoring Sections Optimization of The Main Stream Of Heilongjiang River (Harbin Institute of Technology, 2012)

[7] Wu W.Q., Chen Q.W., Li M.J., Acta Scientiae Circumstantiae 30, 1537-1542 (2010)

[8] Shi T.C., Wang F.E., Fang. X.B., Acta Scientiae Circumstantiae 30, 631-640 (2010)

[9] Yin H.Q., Xin,Y.H., Environmental Protection Science 41, 48-52 (2015)

[10]Tang D.Y., Journal of Anhui Agricultural Sciences, 39, 21265-21267 (2011)

[11]Ma X.Y., Du Z.L., Yue Z.C., Water Resources Protection 6, 31-34 (2014)

[12] Xu Z.M., Han Y.P., Wang P.Y., Yellow River 31, 74-76 (2009)

[13] Yang T., China Water Resources 8, 29-30 (2014)

[14] Yue Z.C., Ma X.Y., Zhang H.W., Yellow River, 37, 36-39 (2015)

[15] Zhu Y., Study On River Reconstruction For The Nigxia Reach Of The Yeloow River (Xi'an University of Technology, 2003) 